\title{
Genetic Exceptionalism, Revisionism, Pluralism and Convergence In The Ethics of Insurance: Response to Commentators
}

\begin{abstract}
:
I would like to thank all of the commentators for their insightful analyses of 'Genetic information, insurance and a pluralistic approach to justice'; I learnt a great deal from them all. Naturally, I cannot do justice to all of their criticisms in this brief response; instead, I shall use their remarks to prompt some clarificatory points about my arguments in the hope that this will help readers to draw their own conclusions about the various points of disagreement. I focus particularly on comments regarding the role of genetic exceptionalism, the issue of revisionism, and the role of pluralism in achieving convergence in cases of ethical disagreement.
\end{abstract}

I would like to begin by thanking all of the commentators for their insightful analyses of 'Genetic information, insurance and a pluralistic approach to justice'; I learnt a great deal from them all. Naturally, I cannot do justice to all of their criticisms in this brief response; instead, I shall use their remarks to prompt some clarificatory points about my arguments in the hope that this will help readers to draw their own conclusions about the various points of disagreement.

My aim in the paper was modest; I aimed to argue that considerations of justice do not speak unequivocally against the use of Genetic Test Results (GTRs) in insurance, and that a pluralist approach may lend support to some limited uses. This represents a compromise position between outright prohibition, and using GTRs in an insurance market in accordance with purely commercial principles. Notably, this conclusion is compatible with the thought that there may be other very strong moral reasons in favour of prohibition. These include concerns about privacy, as well as the consequentialist and human rights considerations that Tiller and Delatyki rightly highlight (1).

Of course, considerations of justice are not orthogonal to questions regarding the right against genetic discrimination, since such a right might plausibly be supported by appeal to broadly egalitarian considerations. Indeed, one important challenge for the rights-based argument for prohibition is to defend the strong degree of genetic exceptionalism it connotes. As I briefly suggested in the paper, broadly egalitarian arguments might be invoked in an attempt to justify at least some degree of genetic exceptionalism here. Notably though, in her commentary, Feiring expresses scepticism about the view of genetic exceptionalism that is implicit in my acceptance of the idea that the use of GTRs in insurance warrants its own specific guidance (2). Given the different views on this matter evident in the commentaries, there is still a need for further analysis about whether any degree of genetic exceptionalism is warranted in this context.

My pluralist argument for a compromise position drew on three broad principles that aimed to capture quite disparate views of justice that might be invoked in this context. This strategy is problematic in some ways, as Holm points out (3), but it does have the virtue of ensuring that the discussion of the issue is inclusive. Nonetheless, O'Neill's criticism of my proposed Principle of Equal Access suggests an important clarificatory remark about that principle (4). This principle was outlined in the context of a discussion about the badness of inequality; so, when the principle states that 'Differential access to insurance is bad unless it is grounded by an inequality that is not unjust.', the badness it refers to is the badness of the inequality that such differential access manifests. The principle claims only that certain kinds of differential access may not involve bad forms of inequality. It is therefore compatible with the 
claim that differential access could still be bad or unjust in other ways, including those that O’Neill's example helpfully illustrates.

The principle of equity also warrants comment. My intention for invoking this principle was not simply because policy in this area must be palatable to industry. I strongly agree with Tiller and Delatyki that we should not make this assumption (1). But it is, I believe, a mistake to disregard the conception of fairness that underlies existing mutualistic insurance arrangements, and to refrain from considering whether it has some form of deeper moral justification. My suggestion is that it may receive support from the quasi-libertarian considerations I described in the paper. In highlighting that it has such support, I did not mean to claim that the principle was incontestable in the manner that concerns O'Neill (4), or to beg any questions that I did not also beg in claiming that considerations of need and equality have moral relevance in this sphere, according to prominent theories of justice.

In view of the fact that the principle of equity has quite different practical implications from the principles of equal access and need in this context, we need some way of managing this disagreement. Feiring helpfully articulates some of the different methodological approaches that can be taken here (2). Fundamentally, we must choose to either (i) defend one set of principles over the other and adopt their potentially revisionary practical implications, or (ii) accommodate both sets by forging a compromise position within a pluralistic framework. I chose the latter strategy, but many others, (including O’Neill (5)) have adopted the former. I have great sympathy for this former approach, and I did not mean to suggest that the revisionism it involves means that it is wrong-headed. But, to repeat a claim from the paper, revisionist policies will garner only as much support as the justifying theories that undergird them; and I am sceptical of the sway that even convincing philosophical theories can have in the policy arena. Perhaps unduly so; perhaps not (6).

Against this scepticism, both Tiller and Delatyki and Holm highlight countries that have prohibited the use of GTRs as examples of extant revisionist policies $(1,3)$. However, this is not revisionism of a degree that $I$ take to raise significant issues; the revisionism $I$ have in mind concerns policies that would involve changing long-standing and widely accepted practices, such as the existence of mutualistic schemes for certain kinds of insurance, or the use of certain kinds of information that is widely accepted in those schemes (such as information about an individual's family history). Notably then, the issue of revisionism is not significant if the proposal is merely that policy-makers should prohibit the use of GTRs alone, without considering whether this position entails that they should also prohibit the use of other analogous information that insurers already use, or to otherwise restrict the scope of mutualistic schemes. Such an approach might lead to inconsistencies that are philosophically unpalatable, but it would not be problematically revisionist in the sense that I was alluded to in the paper.

It is also worth stressing that I did not adopt strategy (ii) on the basis of a belief that we should reject any form of revisionism that does not receive total pluralistic support, a concern that Holm raises (3). Rather, my thought in the passage Holm cites was that if revisionism did in fact receive total pluralistic support, then there would be no real need to choose between strategies (i) and (ii), as they would have the same outcome. In highlighting the absence of total pluralistic support, I meant only to imply that there still is a need to make a choice between these strategies.

There are interesting philosophical and political questions about how we should make the choice between (i) and (ii). Rather than engage in these questions, I believe that there is some value in outlining the compromise position that strategy (ii) might imply. Perhaps the most significant aspect of this analysis is that, at present, this compromise position has strikingly similar practical implications to non-pluralist approaches that support prohibition. That is an important finding because the compromise position currently supports prohibition in a manner that not only avoids the revisionist connotations of (i) and strong forms of genetic exceptionalism; it also 
does so by significantly relying on the very understanding of justice and fairness that the ABI invokes to justify the use of GTRs in the Code. It therefore represents, I believe, a powerful argument for opponents of the use of GTRs in the current context.

Despite this point of consensus, the compromise position I have defended does allow for the possibility that GTRs could, in other circumstances, be used in insurance in a manner that is compatible with the demands of a pluralist conception of justice. This will be the case where the following three conditions obtain:

(a) the basic needs of individuals are met by existing social arrangements (in a manner that satisfies the principles of equal access and need)

(b) there are good reasons to meet a demand for insurance that affords protection beyond that which constitutes a basic need.

(c) general adverse selection in that scheme is likely if GTRs are not used to inform risk classification.

By virtue of (a), I do not believe that my arguments here imply that the NHS should not be created if it did not already exist, as O’Neill suggests (4). However, I accept that there is likely to be significant disagreement about how we should operationalise the concept of basic needs in condition (a). I once again direct the interested reader to O'Neill's insightful treatment of that issue (5). Crucially, I did not claim that (a)-(c) are met by the substantive content of the Code (particularly given the permissible tests and financial limits it stipulates) in its current form. Yet, in addressing the ethics of the Code, I believe we should recognise that its spirit is at least is compatible with a pluralist approach to justice. Recognising this does not settle the ethics of the matter; but it should help broaden our discussion.

1. Tiller J, Delatycki MB. Genetic discrimination in life insurance: a human rights issue. Journal of Medical Ethics. 2021 Jul 1;47(7):484-5.

2. Feiring E. Social insurance, mutualistic insurance and genetic information. Journal of Medical Ethics. 2021 Jul 1;47(7):486-7.

3. Holm S. Genetic information, discrimination, philosophical pluralism and politics. Journal of Medical Ethics. 2021 Jul 1;47(7):480-1.

4. O’Neill M. Genetic information, social justice, and risk-sharing institutions. Journal of Medical Ethics. 2021 Jul 1;47(7):482-3.

5. O’Neill M. Genetic Information, Life Insurance, and Social Justice. 2006 Oct 1;567-92.

6. Savulescu J. Bioethics: why philosophy is essential for progress. 2015 Jan 1;28-33. 